\title{
Sex Differences in Hormonal Modulation of Anxiety Measured with Light-Enhanced Startle: Possible Role for Arginine Vasopressin in the Male
}

\author{
Donna Toufexis, Carrie Davis, Alexis Hammond, and Michael Davis \\ Department of Psychiatry, Yerkes National Primate Center, Emory University, Atlanta, Georgia 30329
}

\begin{abstract}
Increased acoustic startle in the presence of bright ambient light, a phenomenon called light-enhanced startle (LES), is dependent on the bed nucleus of the stria terminalis. In contrast to gonadally intact male rats, LES was seen reliably in castrated male rats and in female rats, although it fluctuated significantly with reproductive state. Replacement with testosterone (T) or combined estradiol (E2) and dihydrotestosterone (DHT), but not with either E2 or DHT alone, attenuated LES in castrated rats. However, replacement with T or E2 in ovariectomized rats did not decrease LES. In contrast, no sex difference was seen in the central amygdala-dependent acquisition or expression of fear-potentiated startle. In addition, $\mathrm{T}$ did not reduce expression of fear-potentiated startle in castrated rats. T-replaced castrated males injected centrally with mixed arginine vasopressin (AVP) V1a/b receptor antagonists daily throughout the replacement period failed to show a reduction in the expression of LES. These data suggest that $T$ attenuates LES, but not fear-potentiated startle, through a mechanism that may involve AVP.
\end{abstract}

Key words: amygdala; anxiety; testosterone; sex differences; BNST; estrogen

\section{Introduction}

Our laboratory has characterized an animal model of anxiety termed light-enhanced startle (LES) (Walker and Davis, 1997). In LES, the amplitude of the acoustic startle response is elevated in the presence of a bright ambient light compared with when tested in the dark. This is consistent with many studies demonstrating that bright light is an anxiogenic stimulus to rodents (File and Hyde, 1978; Crawley, 1981).

The bed nucleus of the stria terminalis (BNST) mediates specific types of anxiety and stress responses (for review, see Walker et al., 2003). For example, the BNST is linked to the escape deficits found within the "learned helplessness" model and behavioral and autonomic responses in rats that resemble those in people with anxiety disorder (Maier, 1990; Shekhar and Keim, 2000). The BNST also mediates the aversive effects of morphine withdrawal in rats (Aston-Jones et al., 1999) and corticotropinreleasing factor (CRF)-induced reinstatement of cocaine-seeking behavior after footshock (Erb and Stewart, 1999). Erb et al. (2001) postulate that footshock-induced reinstatement is controlled by a sequential CRF pathway from the central nucleus of the amygdala to the BNST, a pathway also involved in the expression of conditioned defeat in Syrian hamsters (Jasnow et al.,

Received Jan. 11, 2005; revised July 21, 2005; accepted Aug. 14, 2005.

This work was supported by National Institutes of Mental Health Grants MH 47840, MH 58922, MH 52384, and MH 59906, the Woodruff Foundation, the National Science Foundation Science and Technology Center (the Center for Behavioral Neuroscience of the National Science Foundation under agreement number IBN-9876754), and in part by National Institutes of Health Grant RR00165 to the Yerkes National Primate Center.

Correspondence should be addressed to Michael Davis, Department of Psychiatry, Yerkes National Primate Center, Emory University, 954 Gatewood Drive Northeast, Atlanta, GA 30329. E-mail: mdavis4@emory.edu.

DOI:10.1523/JNEUROSCI.0127-05.2005

Copyright $\odot 2005$ Society for Neuroscience $\quad$ 0270-6474/05/259010-07\$15.00/0
2004). Swerdlow et al. (1986) showed that CRF infused into the lateral ventricle of rats increased the magnitude of the acoustic startle reflex for at least $2 \mathrm{~h}$. Studies by Liang et al. (1992) and Lee and Davis (1997a,b) characterized the dose-response of CRF on acoustic startle and demonstrated that CRF-enhanced, like lightenhanced, startle is dependent on the integrity of the BNST and not the amygdala. These studies suggest an important role for the BNST in the control of emotional reactivity, especially in paradigms resulting in sustained behavioral changes.

The BNST is highly sexually dimorphic (del Abril et al., 1987; Herbison and Theodosis, 1993). Moreover, the BNST, as well as the medial nucleus of the amygdala, show a pronounced sexual dimorphism in that the number of neurons that express arginine vasopressin (AVP), and the amount of AVP message within those neurons is significantly higher in male compared with female rats (Miller et al., 1989). All of these sex differences are regulated by the activational and organizational effects of gonadal steroid exposure (al-Shamma and De Vries, 1996). However, the ramifications that these sex differences within the BNST might have on the expression of emotional behavior have not been elucidated. Considering that the incidence of psychopathologies is significantly greater in women than in men (Kornstein, 1997; Weinstock, 1999), it behooves us to determine whether models of fear and anxiety that rely on different parts of the extended amygdala show sex differences and, if so, what the role of gonadal steroids is in these various models.

In our initial studies at Yale University (New Haven, CT), LES was reliably observed in male rats; however, LES in males is highly inconsistent in our new laboratory. In the current study, we compare LES in male and female rats and begin to characterize the 
mechanisms responsible for sex differences in the reactivity to this anxiogenic stimulus.

\section{Materials and Methods Animals}

Sprague Dawley female and male rats (Charles River, Raleigh, NC) were housed in groups of four in our animal facilities. Male and female rats were housed in separate quarters. In studies requiring intracerebroventricular (ICV) cannula placement, animals were housed individually after surgery. On the testing day, animals were taken from our animal facilities, transported in a clear open-topped $11 \times 7 \times 5 \mathrm{~cm}$ rat cage, and placed into a sound-attenuated (mini booth; Industrial Acoustics, Bronx, NY) holding chamber in the testing room. Animals were left undisturbed in the holding chamber for at least $30 \mathrm{~min}$ before the beginning of testing.

\section{Apparatus}

Rats were trained and tested in two identical $8 \times 15 \times 15 \mathrm{~cm}$ Plexiglas and wire mesh cages as described by Cassella and Davis (1986). Background noise ( $60 \mathrm{~dB}$ wideband) and startle stimuli (50 ms white-noise bursts; rise decay, $5 \mathrm{~ms}$ ) were delivered through high-frequency speakers (Radio Shack Supertweeter; Tandy, Fort Worth, TX) located $5 \mathrm{~cm}$ from the front of each cage. Sound-level measurements were made with a Brüel \& Kjaer (Marlborough, MA) model 2235 sound-level meter (A scale; random input) with the microphone (type 4176) located $7 \mathrm{~cm}$ from the center of the speaker, which approximates the distance of the rat's ear from the speaker during testing. Startle response amplitudes were quantified using an Endevco (San Juan Capistrano, CA) 2217E accelerometer. Cage movement produced by the rat's startle response resulted in displacement of the accelerometer, the output of which was integrated, producing a voltage output proportional to the velocity of cage movement. This signal was amplified by an Endevco model 104 amplifier and digitized on a scale of $0-2510$ units by an InstruNET device (model 100B; GW Instruments, Somerville, MA) interfaced to a Macintosh G3 (Apple Computers, Cupertino, CA) computer. Startle amplitude was defined as the maximal peak-to-peak voltage that occurred during the first $300 \mathrm{~ms}$ after onset of the startle-eliciting noise burst.

In the fear-potentiated startle test, the visual conditioned stimulus was a $3.7 \mathrm{~s} \mathrm{light} \mathrm{(200} \mathrm{lux)} \mathrm{produced} \mathrm{by} 25 \mathrm{~W}$ incandescent bulb located $25 \mathrm{~cm}$ above each cage. The unconditioned stimulus was a $0.5 \mathrm{~s} 0.4 \mathrm{~mA}$ shock delivered through the four floor bars as described by Walker and Davis (1997). The presentation and sequencing of all stimuli were under the control of the Macintosh G3 computer using custom-designed software (The Experimenter; Glassbeads, Newton, CT).

\section{Surgery}

Rats were anesthetized with a ketamine/xylazine mixture (ketamine, 100 $\mathrm{mg} / 100 \mathrm{ml}$; xylazine, $20 \mathrm{mg} / \mathrm{ml}$ at $1 \mathrm{cc} / \mathrm{kg}$ of body weight) administered intraperitoneally and implanted with a cannula (guide cannula 313-G; cut $6 \mathrm{~mm}$ beneath the base; Plastics One, Roanoke, VA) directed at the lateral ventricle, nosebar set at $+5 \mathrm{~mm}$ (coordinates with respect to bregma: $0 \mathrm{~mm}$ anteroposterior, $\pm 1.6 \mathrm{~mm}$ mediolateral, $-5 \mathrm{~mm}$ dorsoventral).

\section{Matching procedure}

Rats were presented with $30,95 \mathrm{~dB}, 50$ ms bursts of white noise (startle stimuli) at a $30 \mathrm{~s}$ interstimulus interval (ISI). The rats were divided into groups so that each group had equivalent mean startle amplitudes across the 30 startle stimuli. For the hormone replacement experiments, rats were tested for LES as described below and matched into groups based on the magnitude of their LES.

\section{Light-enhanced startle}

Animals were placed into the startle cages in a dark chamber and after a 5 min acclimation period presented with 30 startle stimuli at $30 \mathrm{~s} \mathrm{ISI,} \mathrm{which}$ constituted phase I. At the conclusion of phase I, rats were removed from the startle chamber and placed back in their transport cages on an adjacent, well lit table for $\sim 5 \mathrm{~min}$. Rats were then placed back into the startle chamber for phase II, which was a repeat of phase I with either continued darkness or a change to high illumination (200 lux), depending on the experiment. The dependent variable was the difference between startle amplitude when phase I to phase II was from dark to dark compared with when phase I to phase II was from dark to light.

\section{Fear-potentiated startle training}

Two days after matching, rats were placed in the startle test cages and 5 min later given 10 light-shock pairings consisting of a 3.7 s, 200 lux light coterminating with a $0.5 \mathrm{~s}, 0.4 \mathrm{~mA}$ footshock at an average intertrial interval of $2 \mathrm{~min}$ (range, 2-4 min). This procedure was repeated the following day.

\section{Fear-potentiated startle testing}

Eight days later, all animals were returned to the training chambers and presented with $30,95 \mathrm{~dB}$ startle stimuli (noise-alone trials) at a $30 \mathrm{~s}$ ISI followed $30 \mathrm{~s}$ later by the first of 30 light plus startle stimulus trials (light-noise trials) and 30 noise-alone trials in a balanced, irregular order. On the light-noise trials, the startle stimulus occurred $3.2 \mathrm{~s}$ after onset of the light.

\section{Slow acquisition fear-potentiated startle training}

This paradigm is a modification of fear-potentiated startle training in which two training trials/session are given over the course of several days. On training days 1 and 2 and all even days thereafter, rats underwent a test-train procedure consisting of a randomized sequence of 10 startle stimuli: five startle noise bursts alone and five startle noise bursts presented $3.2 \mathrm{~s}$ after the onset of a 3.7 light followed by two training (lightshock) trials consisting of a $3.7 \mathrm{~s}$ light coterminating with a $0.5 \mathrm{~s} 0.4 \mathrm{~mA}$ shock. On training day 3 and all odd days thereafter, the training trials were given at the beginning of the 10 startle stimuli (train-test day).

\section{Data analysis}

Fear-potentiated startle was calculated for each rat as a difference between the startle response in the presence of the conditioned cue (the light) and the startle response in the absence of the conditioned cue.

\section{Specific experiments}

\section{Experiment 1: comparison of light-enhanced startle between male} and female intact and gonadectomized rats

Rationale. We observed previously that LES is inconsistent and variable in intact male rats. Before this, no data were available on LES in female rats or the effect, if any, of reproductive state in female rats. The following experiment was undertaken to address these questions. The elimination of gonadal steroids in both sexes was included to examine whether the presence of these hormones was important for expression of LES.

Method. Gonadally intact male $(n=16)$ and female $(n=16)$ rats housed at least 2 weeks in our animal facilities were matched as described above and tested for LES. Ovariectomized (OVX) females $(n=12)$ and castrated male rats $(n=10)$ were tested in a similar manner 3 weeks after gonadectomy. In addition, one group of pregnant rats $(n=12)$ was tested on days 15 and 16 of pregnancy, and one group of postpartum females $(n=13)$ was tested on days 10 and 11 of lactation.

Experiment 2: light-enhanced startle in gonadectomized male and female rats: the effect of testosterone and estradiol

Rationale. Data from experiment 1 suggested that the presence of testosterone $(\mathrm{T})$ was involved in reducing LES in male rats, whereas the presence of fluctuating levels of estradiol (E2) and progesterone were not involved in reducing LES in female rats. The following experiment tested whether replacement of testosterone or the major metabolite of testosterone, estradiol, would modulate LES in gonadectomized male and female rats.

Method. Three weeks after gonadectomy, groups of male and female rats were tested for LES as described above. After this, rats were separated into two groups such that both groups exhibited a similar level of LES. Rats from the female group were separated in a similar manner. One 
group of males $(n=13)$ and one group of females $(n=14)$ were implanted with SILASTIC capsules [ $36 \mathrm{~mm}$; inner diameter (I.D.), $0.078 \mathrm{in}$; outer diameter (O.D.), 0.125 in] filled with testosterone. The other groups of male $(n=11)$ and female $(n=14)$ rats were implanted with blank SILASTIC capsules. Eight days later, rats were retested for LES. The same experiment was then performed with SILASTIC tubing containing $17 \beta$-estradiol ( $36 \mathrm{~mm}$; I.D., 0.078 in; O.D., 0.125 in) (Sigma, St. Louis, MO) or blank tubing (males, $n=6$ per group; females, $n=8$ per group).

Experiment 3A: the effect of dihydrotestosterone and combined dihydrotestosterone plus estrogen on light-enhanced startle in castrated male rats

Rationale. Whereas testosterone reduced LES in castrated male rats, estradiol did not have any effect. Testosterone is either aromatized into estrogens or reduced into dihydrotestosterone (DHT). This experiment examines the effect of DHT alone or the combination of the two major metabolites of testosterone, DHT and estradiol, on LES in castrated male rats.

Method. Three weeks after castration, male rats $(n=15)$ were tested for LES as described above. After this, male rats were separated into two groups such that both groups exhibited a similar level of LES. One group was replaced with SILASTIC capsules containing DHT (Sigma), and the other group was implanted with blank SILASTIC tubing. Eight days later, rats were retested for LES. A final experiment using double implantation of SILASTIC capsules [one containing DHT and one containing E2 was done on a third group of castrated rats $(n=8)]$. In this experiment, the control group $(n=7)$ was implanted with two empty SILASTIC capsules.

\section{Experiment 3B: the effect of long-term replacement of E2 and}

DHT on light-enhanced startle in castrated male rats

Rationale. Experiment $3 \mathrm{~A}$ indicated that both metabolites of testosterone were necessary for the decrease in LES elicited by testosterone after $8 \mathrm{~d}$ of replacement. The following experiment examined whether more longterm exposure to estradiol or DHT will modulate LES.

Method. Three weeks after castration, male rats $(n=15)$ were tested for LES as described above. After this, male rats were separated into three groups such that all groups exhibited similar levels of LES. One group was replaced with SILASTIC capsules containing E2 (dimensions as above), one group was replaced with SILASTIC tubing containing DHT (dimensions as above), and the last group was implanted with blank SILASTIC tubing ( $n=5$ in each group). Rats were retested for LES as described above 8,15 , and $22 \mathrm{~d}$ after implantation of SILASTIC capsules.

\section{Experiment 4: effects of excess $T$ in intact males}

Rationale. Testosterone replacement reduced LES in castrated males but not in ovariectomized females. The following experiment investigated whether supplemental testosterone would decrease LES in gonadally intact male rats.

Method. Intact males were implanted with T-filled $(n=7)$ or blank $(n=7)$ capsules and tested for LES $8 \mathrm{~d}$ later.

\section{Experiment 5: the effect of central AVP receptor antagonism on} testosterone-induced attenuation of light-enhanced startle in castrated rats

Rationale. LES is dependent on the BNST, a highly sexually dimorphic structure wherein the size and number of AVP neurons are significantly higher in male versus female rats (van Leeuwen et al., 1985; Miller et al., 1989). BNST AVP peptide expression is dependent on the presence of gonadal steroids in both sexes (De Vries et al., 1994a). This experiment examined whether there is a connection between the blunting effect of testosterone on LES in male rats and activation of central AVP receptors.

Method. Castrated rats $(n=24)$ underwent ICV cannulation surgery as described above and were allowed a 1 week recovery period. Subsequent to this, all rats were tested for LES as described above and separated into two groups such that the magnitude of LES was similar in each. One day after the initial test for LES, all groups were replaced with SILASTIC capsules containing T. One group $(n=5)$ of T-replaced males received eight daily ICV injections of the AVP $\mathrm{Vla} / \mathrm{b}$ receptor antagonist $\mathrm{d}\left(\mathrm{CH}_{2}\right)_{5}[\operatorname{try}(\mathrm{me})]$ AVP $[500 \mathrm{ng} / 5 \mu \mathrm{l}$ artificial CSF (aCSF)], and one group of T-replaced males $(n=7)$ received ICV injections of the AVP
$\mathrm{V} 1 \mathrm{a} / \mathrm{b}$ receptor antagonist (1b-mecapto-b-b-cyclopentame thylenepropionicacid)-2-(O-methyltyrosine)AVP (500 ng/5 $\mu \mathrm{laCSF})$. Another group of T-replaced castrated rats $(n=12)$ received eight daily ICV injections of vehicle (aCSF). After these treatments, all rats were retested for LES.

\section{Experiment 6A: comparison of fear-potentiated startle in intact} male and female rats

Rationale. The preceding studies indicated the presence of a sex difference in the expression of light-enhanced startle, which, as mentioned previously, is dependent on the BNST. The purpose of this experiment was to determine whether a gender difference also exists in the expression of fear-potentiated startle, a phenomenon dependent on activation of the central nucleus of the amygdala and independent of the BNST. In addition, by using a training paradigm in which group differences in learning can be detected, we also looked for sex differences in the acquisition of fear-potentiated startle.

Method. In this experiment, we used a modification of fear conditioning called "slow acquisition fear conditioning," which allows us to examine acquisition and expression over an extended period of time. Gonadally intact male $(n=8)$ and female $(n=10)$ rats were trained over a period of $8 \mathrm{~d}$ to associate the appearance of a light with a mild footshock, as described above.

\section{Experiment 6B: the effect of testosterone on fear-potentiated startle} in castrated rats

Rationale. Previous studies in this investigation indicated that testosterone reduces the expression of LES. This experiment examined whether $\mathrm{T}$ has a similar effect on fear-potentiated startle in male rats.

Method. Castrated rats $(n=16)$ were trained for fear-potentiated startle as described above. After training, eight rats were implanted with SILASTIC capsules containing testosterone, and eight rats were implanted with blank SILASTIC capsules. Eight days later, rats were tested for the expression of fear-potentiated startle as described above.

\section{Statistical analysis}

Group differences in light-enhanced and fear-potentiated startle were analyzed using ANOVA followed by post hoc analysis (Fisher's least significant difference) if required.

\section{Results}

Experiment 1: comparison of light-enhanced startle between male and female intact and gonadectomized rats

Figure 1 shows LES in cycling, OVX, pregnant, and lactating females and intact as well as castrated males. ANOVA indicted a significant difference in LES among groups $\left(F_{(5,73)}=3.38 ; p<\right.$ $0.01)$. Post hoc analysis showed a significant decrease in lightenhanced startle in intact males compared with intact females $(p<0.01)$, castrated males $(p<0.05)$, and pregnant females $(p<0.02)$ and a near-significant difference compared with lactating females $(p<0.06)$. When data from cycling, pregnant, and lactating females were compared in a separate analyses, results showed a significant difference in LES across reproductive state $\left(F_{(2,38)}=3.89 ; p<0.03\right)$. Post hoc analysis showed significant increases in light-enhanced startle in pregnant females compared with cycling females $(p<0.04)$ and in pregnant females compared with lactating females $(p<0.01)$.

Experiment 2: light-enhanced startle in gonadectomized male and female rats: the effect of testosterone and estradiol

Table 1 shows testosterone levels in castrated male rats after $8 \mathrm{~d}$ of replacement with T-filled or empty (Blank) SILASTIC tubing. Figure 2, $A$ and $B$, shows the effect of testosterone and estradiol on LES in gonadectomized male rats. Testosterone significantly reduced LES in castrated males $\left(F_{(1,22)}=4.37 ; p<0.05\right)$ but was 


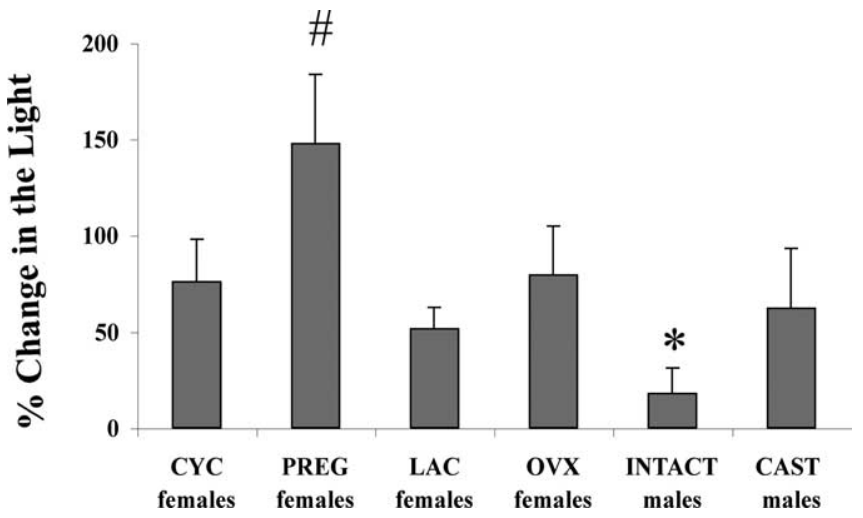

Figure 1. Comparison of light-enhanced startle among females in different reproductive states: cycling (CYC; $n=16)$, pregnant (PREG; days 15 and 16 of gestation; $n=12$ ), and lactating (LAC; postpartum days 10 and $11 ; n=13$ ) as well as ovariectomized female rats ( $n=$ 12) and intact (INTACT; $n=16$ ) and castrated (CAST; $n=10$ ) male rats. In this and all the figures that follow, LES is measured as percentage increase in startle when going from dark to light divided by the percentage increase in startle when going from dark to dark \pm SEM. \# indicates a significant difference in the expression of light-enhanced startle between pregnant females compared with lactating and cycling females. * indicates a significant difference in LES between intact males and cycling and pregnant females, as well as between intact and castrated males.

Table 1. Plasma testosterone levels in a representative group of castrated male rats replaced with testosterone-filled or blank SILASTIC capsules for $\mathbf{8 d}$

\begin{tabular}{ll}
\hline Group & $\mathrm{ng} / \mathrm{ml}$ \\
\hline Testosterone-replaced & $5.385 \pm 0.7020^{*}$ \\
Blanks & $1.15 \pm 0.046291$ \\
\hline
\end{tabular}

* The asterisk indicates significantly higher T levels than rats implanted with blank SILASTIC tubing.

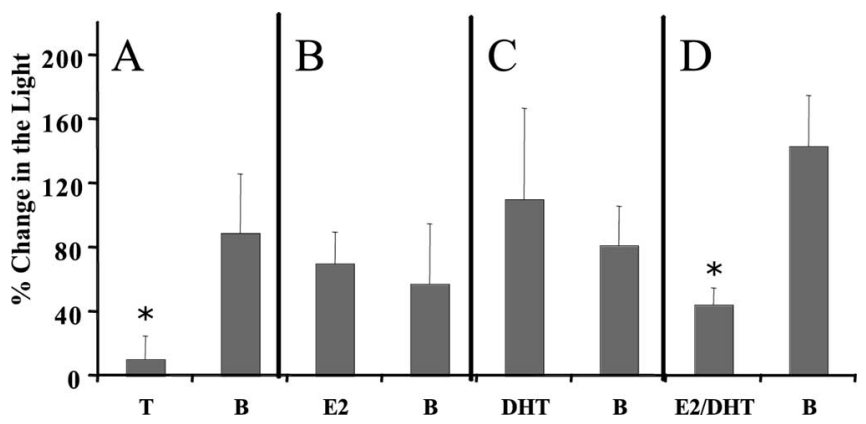

Figure 2. Light-enhanced startle \pm SEM in gonadectomized males after $8 \mathrm{~d}$ of replacement with the following: empty SILASTIC tubing [blanks (B)] ( $n=11)$ or SILASTIC tubing containing $\mathrm{T}(n=13)(A)$; empty SILASTIC tubing (B) $(n=6)$ or SILASTIC tubing filled with E2 $(n=6$ males) (B); blank SILASTIC tubing (B) $(n=7)$ or SILASTIC tubing filled with DHT $(n=8)(\boldsymbol{C})$, and two empty SILASTIC tubes (B) $(n=7)$ or two SILASTIC tubes [1 containing $17 \beta$-estradiol and 1 containing DHT (E2/DHT)] $(n=8)(D)$. ${ }^{*}$ indicates a significant difference between blank and hormone-replaced gonadectomized male rats.

without effect in OVX females. Estrogen had no effect in either castrated or OVX rats (data for females rats with T or E2 not shown).

Experiment 3A: the effect of DHT and combined DHT plus estrogen on light-enhanced startle in castrated male rats Figure 2, $C$ and $D$, shows the effect of DHT and DHT plus estrogen on LES in castrated rats. Combined DHT/E2 significantly reduced LES $\left(F_{(1,13)}=9.39 ; p<0.01\right)$. DHT alone did not significantly reduce LES nor did E2 alone (Fig. 2).

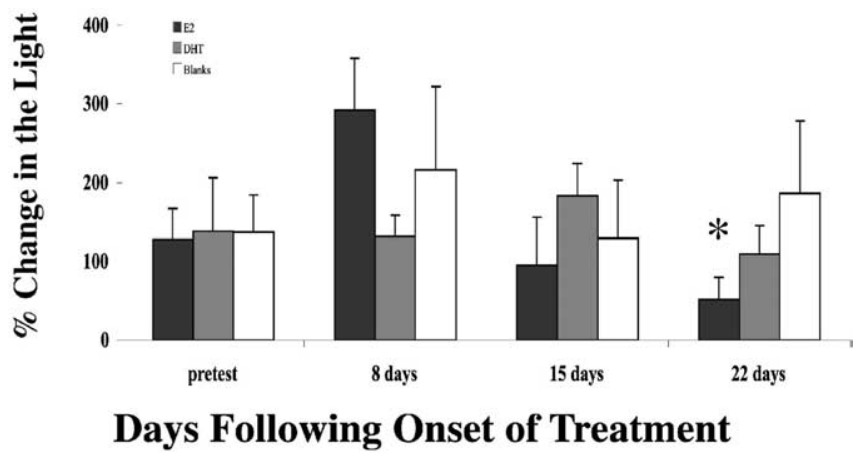

Figure 3. Light-enhanced startle \pm SEM in groups of gonadectomized steroid-replaced males tested three times over the course of $22 \mathrm{~d}$ with SILASTIC tubing containing either E2 (black bars) or DHT (gray bars) or empty tubes (blank; white bars). $n=5$ for all groups. * indicates a significant change in LES over $22 \mathrm{~d}$ in the E2-replaced group.

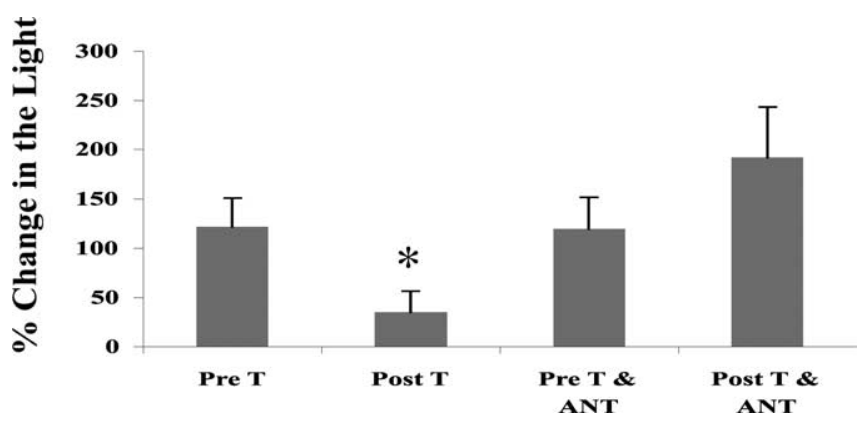

Figure 4. Light-enhanced startle \pm SEM in gonadectomized male rats before (pre-T) and after (post-T) $8 \mathrm{~d}$ of testosterone replacement in rats given either daily ICV injections of an AVP $\mathrm{V} 1 \mathrm{a} / \mathrm{b}$ receptor antagonist or vehicle throughout the replacement period ( $n=12$ per group). * indicates a significant difference in LES from pre-T to post-T in rats injected with vehicle versus those injected with antagonist (ANT).

Experiment 3B: the effect of long-term replacement of E2 and DHT on light-enhanced startle in castrated male rats

Figure $3 B$ shows the effect of E2 and DHT replacement over the course of $22 \mathrm{~d}$. LES was significantly attenuated over time in E2-replaced rats $\left(F_{(3,16)}=4.24 ; p<0.02\right)$. LES did not change over time in DHT-replaced or blank-implanted castrated males. There were no significant group differences at any of the particular time points but only over the complete course of the experiment for the E2 group.

\section{Experiment 4: effects of excess $\mathrm{T}$ in intact males}

$\mathrm{T}$ given to gonadally intact rats further attenuated the reducing effect of endogenous $\mathrm{T}$ on the startle response to light. Increased startle in the light of intact males replaced with blank SILASTIC tubing was $54 \pm 48 \%$. Intact males replaced with testosterone was $-5 \pm 18 \%$ (data not shown).

Experiment 5: the effect of central AVP receptor antagonism on testosterone-induced attenuation of light-enhanced startle in castrated rats

Figure 4 shows LES in castrated male rats replaced with $\mathrm{T}$ along with ICV injections of either vehicle or the $\mathrm{V} 1 \mathrm{a} / \mathrm{b}$ receptor antagonists over the course of T replacement. An overall ANOVA using treatment $(\mathrm{V} 1 \mathrm{a} / \mathrm{b}$ antagonist vs vehicle) and type of $\mathrm{Vla} / \mathrm{b}$ antagonist as between-subjects factors and time (pre-T vs post-T) as a within-subjects factor found a significant treatment-by-time interaction $\left(F_{(1,20)}=4.214 ; p<0.05\right)$, reflecting the fact that $\mathrm{T}$ reduced LES in vehicle-treated but not V1a antagonist-treated 
rats. There was no three-way interaction, indicating there was no statistical difference in the ability of the two antagonists to block the effect of $\mathrm{T}\left(F_{(1,20)}\right.$ $=2.04 ; p>0.10)$, and hence the data were combined in Figure 4.

\section{Experiment 6A: comparison of fear- potentiated startle in intact male and female rats}

Figure $5 A$ shows the acquisition and expression of fear-potentiated startle for intact male and female rats over the training period of $8 \mathrm{~d}$. There was a significant increase in fear-potentiated startle over time $\left(F_{(4,64)}=6.30 ; p<\right.$ $0.002)$. There was no significant difference between males and females over time $\left(F_{(4,64)}=0.69 ; p<0.605\right)$. In addition, there was no significant difference in the magnitude of fearpotentiated startle between male and female rats, although male rats showed a tendency for enhanced fear-potentiated startle compared with females $\left(F_{(1,16)}=2.10 ; p<0.167\right)$. However, in this experiment, males showed a slight unconditioned increase in startle in the presence of the light before training, which may account for some of the increased reactivity to the light in male rats. Both testosterone-replaced capsules and blanks displayed significant fear-potentiated startle (see Fig. 5B). Chronic ( $8 \mathrm{~d}$ ) exposure to testosterone did not affect the expression of fear-potentiated startle in castrated rats $\left(F_{(1,14)}=0.013 ; p>0.911\right)$. There was no effect of testosterone on baseline startle response [testosterone noise alone, $1.684 \pm 0.241$; vehicle noise alone, $2.186 \pm 0.505$ (in arbitrary units)].

\section{Discussion}

In this study, the role of gender and gonadal steroids was measured using LES. LES was seen consistently in female rats, although the magnitude of this effect varied from one group of female rats to another. In contrast, male rats showed rather low and quite variable LES, similar to what we have observed for male rats in several of our previous experiments. This gender difference was not seen in the acquisition or expression of fearpotentiated startle. Castration of male rats produced a more consistent LES, similar in magnitude to that observed in female rats. Replacement of T, at high physiological doses, significantly attenuated LES in castrated males and further reduced it in intact male rats but had no effect on fear-potentiated startle in castrated male rats. This indicates that circulating $\mathrm{T}$ acts to decrease the response of male rats to the anxiogenic stimulus of a bright light but is ineffective for reducing the response to a conditioned fear.

Eight days of T replacement did not blunt the expression of LES in T-replaced OVX females. Furthermore, T-replaced males that received ICV injection of an AVP V1a/b receptor antagonist once daily throughout the term of T replacement did not show the reduction in LES normally observed after T exposure, suggesting that $\mathrm{T}$ attenuates LES through a mechanism involving AVP.

The attenuation of LES by T complements several studies that also indicate that $\mathrm{T}$ can have anxiolytic effects in several measures of anxiety in rats. Both T-replaced and T-administered castrated male rats exhibited increased open-arm exploration in the ele-

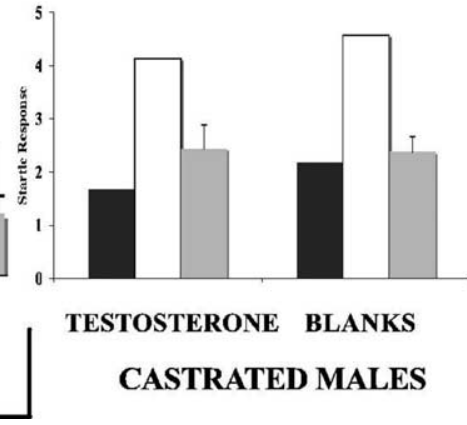

vated plus maze (Bitran et al., 1993; Frye and Seliga, 2001). Female rats injected with T, DHT (the nonaromatizable metabolite of T), or $3 \alpha$-diol (the reduced neuroactive metabolite of DHT) showed increased entries into the open field and increased openarm time in the elevated plus maze (Frye and Lacey, 2001). Male rats exposed to high levels of $\mathrm{T}$ showed an increase in punished responding in the Vogel conflict test (Bing et al., 1998). Interestingly, T has been shown to ameliorate mood in hypogonadal and aged men and in perimenopausal and elderly women. $\mathrm{T}$ has also been shown to reduce activation of the hypothalamic-pituitaryadrenal (HPA) axis in rats, providing yet another possible mechanism whereby $\mathrm{T}$ reduces indices of anxiety (Meaney et al., 1993; Viau and Meaney, 1996; Viau et al., 2001, 2005; Viau, 2002).

In this study, female rats consistently displayed significant LES; however, the magnitude of this response was sensitive to factors that modulate, or are themselves modulated by, reproductive state. Pregnant rats exhibited significantly higher levels of LES than cycling or lactating rats. Pregnancy and lactation produce a myriad of behavioral changes including altered emotional and stress responses. However, whereas lactation results in decreases in anxiety-like behavior (Fleming and Luebke, 1981; Hard and Hansen, 1985; Toufexis et al., 1999), pregnant rats show increased anxiety on the elevated plus maze (Neumann et al., 1998; Neumann, 2001), a significant rise in baseline startle response (Young and Cook, 2004), and more fear in the shock probe burying test (Picazo et al., 1993). The present data indicating that pregnancy increases the emotional response to bright ambient light is consistent with these other studies.

In the current study, $8 \mathrm{~d}$ of $\mathrm{T}$ replacement did not attenuate LES in gonadectomized female rats. In the prenatal and perinatal period, T works to sculpt the male brain, thus setting the stage for the activation of sex-specific responses during adolescence and throughout adulthood. Here, the reduction of LES by exogenous $\mathrm{T}$ was particular to male rats, suggesting that $\mathrm{T}$ was acting on a system that is organized to respond uniquely in males. The BNST constitutes one of the most sexually dimorphic regions of the mammalian brain (for review, see Segovia and Guillamon, 1993; Walker et al., 2003). For example, the BNST shows a sexual dimorphism in that the number of neurons expressing AVP and the amount of AVP peptide are significantly higher in male com- 
pared with female rats (van Leeuwen et al., 1985; Miller et al., 1989). This sex difference is mediated by the early organizational effects of T in males (Han and De Vries, 2003). Moreover, the presence AVP within these brain areas in adult rats of both sexes requires the presence of gonadal steroids (De Vries et al., $1994 a, b)$. In the present study, ICV application of a broadspectrum (mixed V1a and V1b) vasopressin receptor antagonists counteracted the $\mathrm{T}$-induced reduction of LES, suggesting that $\mathrm{T}$ attenuates LES through a mechanism that involves AVP.

The major projection site for BNST AVP is the lateral septum, an area long implicated in the modulation of fear and anxiety (De Vries and Buijs, 1983). The behavioral effects of modulating septal AVP are contradictory. AVP V1a receptor antisense or antagonist treatment have an anxiolytic effect on plus maze behavior in some studies (Landgraf et al., 1995). However, the application of synthetic AVP failed to produce any effect in the plus maze in another study (Liebsch et al., 1996). Moreover, a potent V1/V2 antagonist had no effect on shock-probe burying behavior and reduced open-arm activity (Everts and Koolhaas, 1999). It is possible that these conflicting data result from a nonmonotonic relationship between individual levels of AVP innervation and the response to anxiogenic stimulation. Studies in both rats and mice show that the variation of the lateral septum AVP system within males is as great as that between males and females. Indeed, there is a negative correlation between AVP content and the extent of septal AVP innervation and aggression in male mice and a positive correlation between AVP levels in the septum in rats showing high performance in footshock-induced brightness discrimination (for review, see Koolhaas et al., 1998). Moreover, it has been reported recently that endogenous AVP released in the lateral septum during the forced swim test reduces immobility, whereas the application of a potent V1 antagonist by reverse microdialysis produced the opposite results (Ebner et al., 1999), suggesting that septal AVP is involved in stress-coping behaviors. These results, together with the marked intramale variability in AVP, suggest that emotional responses in male rodents may be exquisitely tied to AVP function within the lateral septum. It is possible that the variability in the expression of LES in male rats observed in this and other studies from our laboratory is related to this phenomenon. Interestingly, studies suggest that androgen regulation of the HPA axis is mediated through the control of AVP in limbic areas, like the BNST (Viau et al., 2001), thus providing evidence that the interaction between T and AVP may be a common mechanism within the brain.

The reduction of LES after T replacement in castrated males was not caused by the individual action of either estrogen or DHT but required the presence of both of these metabolites of testosterone. However, prolonged exposure (22 d) to E2, but not DHT, did attenuate LES in males to a significant degree. Here, once again, is a possible connection with BNST AVP. De Vries et al. (1994a) demonstrated that estrogen replacement resulted in an increase of AVP message within the BNST in both castrated males and a significant but smaller increase in OVX females. Moreover, although DHT had no effect on AVP peptide levels alone, the combination of estrogen and DHT significantly increased the number of BNST cells expressing AVP message over that seen with estrogen alone, and this increase was selective to male rats. Therefore, if the reduction of LES by T is mediated through BNST AVP, one might expect that the most robust effect would occur with both estrogen and DHT present. However, it is possible that the present experimental design ( $8 \mathrm{~d}$ of replacement) did not allow sufficient time for $\mathrm{E} 2$ or $\mathrm{T}$ to have an effect in female rats. Experiments are underway to ascertain whether length of hor- mone exposure is a determinant for hormonal effects in females within this experimental model.

In contrast to LES, $\mathrm{T}$ had no effect on the expression of fearpotentiated startle in male rats. The central nucleus of the amygdala is critical for conditioned fear, whereas the BNST is not, a situation that is exactly the opposite of that for CRF- or light enhanced-startle, which requires activation of the BNST and not the central nucleus of the amygdala (Hitchcock and Davis, 1986; Hitchcock and Davis, 1987; Kim and Davis, 1993; Lee and Davis, 1997b; Walker and Davis, 1997; Gewirtz et al., 1998). This argues that the BNST is not necessary for the elaboration of fear responses evoked by explicit cues but is required for the response to more long-lasting anxiogenic stimuli. Thus, it may be that $\mathrm{T}$ is important for modulating behavioral responses to continuous aversive stimuli rather than situations in which an immediate response would be more adaptive. Indeed, $\mathrm{T}$ enhances memory consolidation in several learning paradigms (Frye and Lacey, 2001; Bimonte-Nelson et al., 2003; Edinger et al., 2004). One can surmise that dampening responses to a continuous anxiogenic stimulus could enhance attention toward, and thus accentuate the ability to learn about, a novel biologically salient stimulus. To address this question, we are currently examining the role that $\mathrm{T}$ plays in the acquisition rather than simply the expression of fearpotentiated startle.

In summary, these studies support a role for $\mathrm{T}$ in the reduction of the behavioral response to the anxiogenic effect of bright ambient light in male, but not female, rats. In addition, the data suggest that the effect of T may be mediated through AVP, perhaps at the BNST or through its projection to the lateral septum.

\section{References}

al-Shamma HA, De Vries GJ (1996) Neurogenesis of the sexually dimorphic vasopressin cells of the bed nucleus of the stria terminalis and amygdala of rats. J Neurobiol 1:91-98.

Aston-Jones G, Delfs JM, Druhan J, Zhu Y (1999) The bed nucleus of the stria terminalis. A target site for noradrenergic actions in opiate withdrawal. Ann NY Acad Sci 877:486-498.

Bimonte-Nelson HA, Singleton RS, Nelson ME, Eckman CB, Barber J, Scott TY, Granholm C (2003) Testosterone, but not nonaromatizable dihydrotestosterone, improves working memory and alters nerve growth factor levels in aged male rats. Exp Neurol 18:1301-1312.

Bing O, Heilig M, Kakoulidis P, Sundblad C, Wiklund L, Eriksson E (1998) High doses of testosterone increase anticonflict behaviour in rat. Eur Neuropsychopharmacol 4:321-323.

Bitran D, Kellogg CK, Hilvers RJ (1993) Treatment with an anabolicandrogenic steroid affects anxiety-related behavior and alters the sensitivity of cortical GABAA receptors in the rat. Horm Behav 4:568-583.

Cassella JV, Davis M (1986) The design and calibration of a startle measurement system. Physiol Behav 3:377-383.

Crawley JN (1981) Neuropharmacologic specificity of a simple animal model for the behavioral actions of benzodiazepines. Pharmacol Biochem Behav 5:695-699.

del Abril A, Segovia S, Guillamon A (1987) The bed nucleus of the stria terminalis in the rat: regional sex differences controlled by gonadal steroids early after birth. Brain Res 429:295-300.

De Vries GJ, Buijs RM (1983) The origin of the vasopressinergic and oxytocinergic innervation of the rat brain with special reference to the lateral septum. Brain Res 273:307-317.

De Vries GJ, Wang Z, Bullock NA, Numan S (1994a) Sex differences in the effects of testosterone and its metabolites on vasopressin messenger RNA levels in the bed nucleus of the stria terminalis of rats. J Neurosci 14:1789-1794.

De Vries GJ, al-Shamma HA, Zhou L (1994b) The sexually dimorphic vasopressin innervation of the brain as a model for steroid modulation of neuropeptide transmission. Ann NY Acad Sci 743:95-120.

Ebner K, Wotjak CT, Holsboer F, Landgraf R, Engelmann M (1999) Vasopressin released within the septal brain area during swim stress modulates the behavioural stress response in rats. Eur J Neurosci 11:997-1002. 
Edinger KL, Lee B, Frye CA (2004) Mnemonic effects of testosterone and its 5alpha-reduced metabolites in the conditioned fear and inhibitory avoidance tasks. Pharmacol Biochem Behav 78:559-568.

Erb S, Stewart J (1999) A role for the bed nucleus of the stria terminalis, but not the amygdala, in the effects of corticotropin-releasing factor on stressinduced reinstatement of cocaine seeking. J Neurosci 19:RC35(1-6).

Erb S, Salmaso N, Rodaros D, Stewart J (2001) A role for the CRFcontaining pathway from central nucleus of the amygdala to bed nucleus of the stria terminalis in the stress-induced reinstatement of cocaine seeking in rats. Psychopharmacology (Berl) 158:360-365.

Everts HG, Koolhaas JM (1999) Differential modulation of lateral septal vasopressin receptor blockade in spatial learning, social recognition, and anxiety-related behaviors in rats. Behav Brain Res 99:7-16.

File SE, Hyde JR (1978) Piracetam-a non-sedative anxiolytic drug? [proceedings] Br J Pharmacol 62:425P-426P.

Fleming AS, Luebke C (1981) Timidity prevents the virgin female rat from being a good mother: emotionality differences between nulliparous and parturient females. Physiol Behav 27:863-868.

Frye CA, Lacey EH (2001) Posttraining androgens' enhancement of cognitive performance is temporally distinct from androgens' increases in affective behavior. Cogn Affect Behav Neurosci 1:172-182.

Frye CA, Seliga AM (2001) Testosterone increases analgesia, anxiolysis, and cognitive performance of male rats. Cogn Affect Behav Neurosci 1:371-378.

Gewirtz JC, McNish KA, Davis M (1998) Lesions of the bed nucleus of the stria terminalis block sensitization of the acoustic startle reflex produced by repeated stress, but not fear potentiated startle. Prog Neuropsychopharmacol Biol Psychiatry 22:625-648.

Han TM, De Vries GJ (2003) Organizational effects of testosterone, estradiol, and dihydrotestosterone on vasopressin mRNA expression in the bed nucleus of the stria terminalis. J Neurobiol 54:502-510.

Hard E, Hansen S (1985) Reduced fearfulness in the lactating rat. Physiol Behav 35:641-643.

Herbison AE, Theodosis DT (1993) Absence of estrogen receptor immunoreactivity in somatostatin (SRIF) neurons of the periventricular nucleus but sexually dimorphic colocalization of estrogen receptor and SRIF immunoreactivities in neurons of the bed nucleus of the stria terminalis. Endocrinology 132:1707-1714.

Hitchcock JM, Davis M (1986) Lesions of the amygdala, but not of the cerebellum or red nucleus, block conditioned fear as measured with the potentiated startle paradigm. Behav Neurosci 100:11-22.

Hitchcock JM, Davis M (1987) Fear potentiated startle using an auditory conditioned stimulus: effect of lesions of the amygdala. Physiol Behav 39:403-408.

Jasnow AM, Davis M, Huhman KL (2004) Involvement of central amygdalar and bed nucleus of the stria terminalis corticotropin-releasing factor in behavioral responses to social defeat. Behav Neurosci 118:1052-1061.

Kim M, Davis M (1993) Electrolytic lesions of the amygdala block acquisition and expression of fear potentiated startle even with extensive training but do not prevent reacquisition. Behav Neurosci 107:580-595.

Koolhaas JM, Everts H, de Ruiter AJ, de Boer SF, Bohus B (1998) Coping with stress in rats and mice differential peptidergic modulation of the amygdala-lateral septum complex. Prog Brain Res 119:437-448.

Kornstein SG (1997) Gender differences in depression: implications for treatment. J Clin Psychiatry [Suppl 58] 15:12-18.

Landgraf R, Gerstberger R, Montkowski A, Probst JC, Wotjak CT, Holsboer F, Engelmann M (1995) V1 vasopressin receptor antisense oligodeoxynucleotide into septum reduces vasopressin binding, social discrimination abilities, and anxiety-related behavior in rats. J Neurosci 15:4250-4258

Lee Y, Davis M (1997a) Role of the septum in the excitatory effect of corticotropin-releasing hormone on the acoustic startle reflex. J Neurosci 17:6424-6433

Lee Y, Davis M (1997b) Role of the hippocampus, the bed nucleus of the stria terminalis, and the amygdala in the excitatory effect of corticotropin- releasing hormone on the acoustic startle reflex. J Neurosci 17:6434-6446.

Liang KC, Melia KR, Miserendino MJ, Falls WA, Campeau S, Davis M (1992) Corticotropin-releasing factor: long-lasting facilitation of the acoustic startle reflex. J Neurosci 12:2303-2312.

Liebsch G, Wotjak CT, Landgraf R, Engelmann M (1996) Septal vasopressin modulates anxiety-related behaviour in rats. Neurosci Lett 217:101-104.

Maier SF (1990) Role of fear in mediating shuttle escape learning deficit produced by inescapable shock. J Exp Psychol Anim Behav Process 16:137-149.

Meaney MJ, Bhatnagar S, Diorio J, Larocque S, Francis D, O’Donnell D, Shanks N, Sharma S, Smythe J, Viau V (1993) Molecular basis for the development of individual differences in the hypothalamic-pituitaryadrenal stress response. Cell Mol Neurobiol 13:321-347.

Miller MA, Vician L, Clifton DK, Dorsa DM (1989) Sex differences in vasopressin neurons in the bed nucleus of the stria terminalis by in situ hybridization. Peptides 10:615-619.

Neumann ID (2001) Alterations in behavioral and neuroendocrine stress coping strategies in pregnant, parturient and lactating rats. Prog Brain Res 133:143-152.

Neumann ID, Wigger A, Liebsch G, Holsboer F, Landgraf R (1998) Increased basal activity of the hypothalamo-pituitary-adrenal axis during pregnancy in rats bred for high anxiety-related behaviour. Psychoneuroendocrinology 23:449-463.

Picazo O, Fernandez-Guasti A (1993) Changes in experimental anxiety during pregnancy and lactation. Physiol Behav 54:295-299.

Segovia S, Guillamon A (1993) Sexual dimorphism in the vomeronasal pathway and sex differences in reproductive behaviors. Brain Res Brain Res Rev 18:51-74.

Shekhar A, Keim SR (2000) LY354740, a potent group II metabotropic glutamate receptor agonist prevents lactate-induced panic-like response in panic-prone rats. Neuropharmacology 27:1139-1146.

Swerdlow NR, Geyer MA, Vale WW, Koob GF (1986) Corticotropinreleasing factor potentiates acoustic startle in rats blockade by chlordiazepoxide. Psychopharmacology (Berl) 88:147-152.

Toufexis DJ, Rochford J, Walker C-D (1999) Lactation-induced reduction in rats' acoustic startle is associated with changes in noradrenergic neurotransmission. Behav Neurosci 113:176-184.

van Leeuwen FW, Caffe AR, De Vries GJ (1985) Vasopressin cells in the bed nucleus of the stria terminalis of the rat: sex differences and the influence of androgens. Brain Res 325:391-394.

Viau V (2002) Functional cross-talk between the hypothalamic-pituitarygonadal and -adrenal axes. J Neuroendocrinol 14:506-513.

Viau V, Meaney MJ (1996) The inhibitory effect of testosterone on hypothalamic-pituitary-adrenal responses to stress is mediated by the medial preoptic area. J Neurosci 16:1866-1876.

Viau V, Soriano L, Dallman MF (2001) Androgens alter corticotropin releasing hormone and arginine vasopressin mRNA within forebrain sites known to regulate activity in the hypothalamic-pituitary-adrenal axis J Neuroendocrinol 13:442-452.

Viau V, Bingham B, Davis J, Lee P, Wong M (2005) Gender and puberty interact on the stress-induced activation of parvocellular neurosecretory neurons and corticotropin-releasing hormone messenger ribonucleic acid expression in the rat. Endocrinology 146:137-146.

Walker DL, Davis M (1997) Double dissociation between the involvement of the bed nucleus of the stria terminalis and the central nucleus of the amygdala in startle increases produced by conditioned versus unconditioned fear. J Neurosci 17:9375-9383.

Walker DL, Toufexis DJ, Davis M (2003) Role of the bed nucleus of the stria terminalis versus the amygdala in fear, stress, and anxiety. Eur J Pharmacol 463:199-216.

Weinstock L (1999) Gender differences in the presentation and management of social anxiety disorder. J Clin Psychiatry [Suppl 60] 9:9-13.

Young BJ, Cook CJ (2004) Stress-induced modification of anxiety in rats is dependent on reproductive status. Physiol Behav 80:569-575. 